\title{
Age and the Length of Hospital Stay in Patients With Sepsis at the ICU Admission can Prolong the Duration of Endotracheal Intubation
}

\author{
Farshid Rahimibashar ${ }^{\circledR}$, Amir Vahedian-Azimi $^{2}{ }^{\circledR}$, Mahmood Salesi $^{3^{\circledR}}$, Masoum Khosh Fetrat $^{4^{*}(}$ \\ 'Department of Anesthesiology and Critical Care, School of Medicine, Hamadan University of Medical Sciences, \\ Hamadan, Iran \\ ${ }^{2}$ Trauma Research Center, Nursing Faculty, Baqiyatallah University of Medical Sciences, Tehran, Iran \\ ${ }^{3}$ Chemical Injuries Research Center, Life Style Institute, Baqiyatallah University of Medical Sciences, Tehran, Iran \\ ${ }^{4}$ Departments of Anesthesiology and Critical Care, Khatamolanbia Hospital, Zahedan University of Medical Sciences, \\ Zahedan, Iran
}

\begin{abstract}
*Corresponding Author: Masoum Khosh Fetrat, MD, Associate Professor, Departments of Anesthesiology and Critical Care, Khatamolanbia Hospital, Zahedan University of Medical Sciences, Zahedan, Iran. Tel: +98-9196017138, Email: drkhoshfetrat@yahoo.com
\end{abstract}

Received November 12, 2020; Accepted December 25, 2020; Online Published January 8, 2021

\begin{abstract}
Background: Endotracheal intubation (EI) associated with mechanical ventilation (MV) is frequently performed in critically ill patients admitted to intensive care unit (ICU) with sepsis.

Objectives: This study aimed to assess the impact of important factors on the duration of tracheal intubation in patients with sepsis at the ICU admission.

Methods: Adult patients admitted to the mixed medical-surgical ICUs with sepsis at the ICU admission who needs prolonged mechanical ventilation (PMV) ( $\geq 21$ days) were included in this retrospective secondary analysis study. The primary outcome was ICU mortality. Baseline demographic and clinical characteristics of all patients were assessed as risk factors associated with the duration of MV by univariate and multivariate Binary logistic regression.

Results: Eighty-five patients required more than 21 days of MV. Out of the 85 patients, $52(61.2 \%)$ patients were intubated within 30 to 34.50 days and 33 (38.8\%) patients had intubation within 34.51 to 65 days, and categorized as PMV and very prolonged MV groups, respectively. Two parameters were significantly associated with very prolonged MV which are as follows: older age 1.229 (95\% Cl: $1.002-1.507, P=0.048$ ) and long hospital stay (LOS) 2.996 (95\% Cl: 1.676-5.356, $P<0.001$ ). No significant survival difference was observed between the two groups of study. (33.3\% vs. $25 \%, P=0.406)$.

Conclusion: Our observations showed that the older age and LOS as pre-ICU stay in patients with positive sepsis at the ICU admission can prolong the duration of intubation. In addition, no significant survival difference was observed between patients with PMV and very prolonged MV.

Keywords: Sepsis, Intensive Care Unit, Endotracheal Intubation, Prolonged Mechanical Ventilation
\end{abstract}

\section{Background}

Sepsis is a major cause of intensive care unit (ICU) admission, which carries a higher mortality rate compared to non-septic ICU patients. ${ }^{1,2}$ The systemic and destructive response of the host to the infection is defined as sepsis. Delayed treatment can lead to severe sepsis and progress to tissue hypoperfusion and hypotension can turn it into septic shock. ${ }^{3,4}$ Endotracheal intubation (EI) is commonly performed in the setting of respiratory failure and shock, and is one of the most commonly performed procedures in ICU patients. ${ }^{5}$ In recent large-scale trials, $40 \%$ to $85 \%$ of patients received this technique, suggesting that a substantial number of patients remained free of EI..$^{6-8}$ It is an essential life-saving intervention; however, this procedure and its duration are associated with several factors.

EI and mechanical ventilation (MV) are undoubtedly necessary in the event of profound hypoxia or loss of consciousness but may rely on medical preference or habits in other cases. EI and artificial ventilation, allowing deep sedation, have been recommended by some researchers in severe sepsis or septic shock patients to minimize diaphragm oxygen intake. ${ }^{9,10}$ In addition, these models have shown that diaphragmatic dysfunction occurs rapidly in shock, ultimately leading to respiratory failure and death. ${ }^{11,12}$ However, the side effects of ventilation and sedation may outweigh the expected benefit for some

Copyright (C) 2021 The Author(s). This is an open-access article distributed under the terms of the Creative Commons Attribution License (http:// creativecommons.org/licenses/by/4.0), which permits unrestricted use, distribution, and reproduction in any medium, provided the original work is properly cited. 
patients. ${ }^{13}$ Among patients who are not initially intubated, those who subsequently need EI may have this procedure delayed. Finally, it is not clear how EI and its initiation timing influence the outcome of patients with sepsis or septic shock. ${ }^{14}$

A prospective multicenter observational study by Darreau et $\mathrm{al}^{15}$ reported that seven parameters were significantly associated with early intubation in patients with septic shock; including Glasgow Coma Scale (GCS), center effect, use of accessory respiratory muscles, lactate level, vasopressor dose, $\mathrm{PH}$, and inability to clear tracheal secretions. Although they concluded that neurological, respiratory, and hemodynamic parameters affected tracheal intubation in septic shock patients, a vast part of the variability of intubation remained unexplained by patient characteristics. On the other hand, patients with very prolonged tracheal intubation had more complications, such as airway injuries, ventilator-associated pneumonia, muscle weakness, pressure ulcers, bacterial nosocomial sepsis, pulmonary embolism, and hyperactive delirium, than patients with low EI duration. ${ }^{16}$

\section{Objectives}

Evidence suggests that the risk of ICU mortality was significantly higher in patients who had prolonged mechanical ventilator (PMV). ${ }^{17,18}$ Hence, the effect of patients' baseline characteristics on it, is still an open field to be explored. Given that the sepsis is one of the factors associated with $\mathrm{PMV},{ }^{19}$ to determine the characteristics associated with prolonged and very prolonged duration of EI in septic patients and the impact of this procedure on mortality, we performed an observational retrospective secondary analysis on the database of 4200 acute respiratory distress syndrome (ARDS) patients from the mixed medical-surgical ICUs of two academic medical centers in Iran.

\section{Methods}

\subsection{Study Design and Participants}

This study was a retrospective secondary analysis of the part of a much bigger project that was a prospective longitudinal cohort study. ${ }^{20}$ In brief, the original study was a prospective longitudinal cohort study conducted on 4200 mixed medical-surgical ICUs patients on MV from two academic teaching hospitals in Tehran, Iran between June 1, 2007, and October 31, 2015. From 4200 ARDS patients in the original data base, we selected 85 patients with sepsis at the admission on MV to investigate the outcomes of patients requiring PMV and very prolonged $\mathrm{MV}$, as well as identifying risk factors associated with EI. Based on the median duration of intubation (days), intubation data were sorted into two categories; PMV (30-34.5 days) and very prolonged MV (34.51-65 days). The inclusion criteria were (a) age $\geq 18$ years, (b) MV duration $\geq 21$ days, and (c) full-code status patients. All study parts were reviewed according to the "Strengthening the Reporting of Observational Studies in Epidemiology for respondent- driven sampling studies" (STROBE-RDS) statement. ${ }^{21}$

\subsection{Definition}

Sepsis was defined based on clinical criteria adopted in 2015 as "suspected or documented infection and an acute increase of $\geq 2$ Sequential (Sepsis-related) Organ Failure Assessment (SOFA) points (a proxy for organ dysfunction)". It was updated in 2016 in sepsis-3 criteria $^{22}$ : "Sepsis is a life-threatening organ dysfunction caused by a dysregulated host response to the infection. For clinical operationalization, organ dysfunction can be represented by an increase in the SOFA score of two points or more, which is associated with an in-hospital mortality greater than $10 \%$ ".

PMV was introduced based on the National Association for Medical Direction of Respiratory Care (NAMDRC) definition "the need for more than 21 consecutive days of MV for more than 6 hours per day". ${ }^{23}$

\subsection{Data Collection and Outcome}

Demographic and clinical characteristics were recorded for these 85 patients, including age, gender, comorbidities based on Charlson Comorbidity Index, ${ }^{24}$ baseline cognitive impairment (CI) determined by the six-item cognitive impairment test (6-CIT), ${ }^{25}$ family engagement determined according to family bedside presence $\geq 2$ hours daily, ${ }^{26}$ acute nursing care determined by requiring $>8$ hours nursing care in an eight- hour-shift, ICU length of stay (LOS), hospital LOS, sedative dose determined in accordance with published recommendations, ${ }^{27}$ and baseline sleep disturbance assessed with the Pittsburgh Sleep Quality Index (PSQI). ${ }^{28}$ Additionally, illness severity was measured by the Simplified Acute Physiology Score (SAPS) II on the day of admission; on $14^{\text {th }}$ and $28^{\text {th }}$ day of ICU stay. ${ }^{29}$ The main outcome variable was ICU mortality, following ICU admission.

\subsection{Statistical Analysis}

Data are presented as mean \pm standard deviation (SD) or percentages. Categorical data were compared using the $\chi^{2}$ test (or Fisher exact test when appropriate); and the continuous data, using the Student $t$ test. In addition, both unadjusted and adjusted logistic regressions were used to estimate the odds ratio (OR) to determine the association of demographic and clinical characteristics with PMV or very prolonged MV. All data were analyzed using the Statistical Package for the Social Sciences (SPSS) 21.0 statistical package (Chicago, IL, USA) and GraphPad Prism $5^{\odot}$ (GraphPad Software Inc., La Jolla, CA), ${ }^{30}$ and two-side $P<0.05$ indicated a statistically significant difference.

\section{Results}

From 4200 patients in the original data base, 85 patients required more than 21 consecutive days of MV for more than 6 hours per day. Among the 85 patients, 52 (61.2\%) patients were intubated within 30 to 34.50 days and 33 (38.8\%) patients had intubation within 34.51 to 65 days, 
which were categorized as PMV and very prolonged MV groups, respectively. The mean \pm SD age of total participants was $65.07 \pm 5.04$ years and more than half of the patients $(67.1 \%)$ were female. The mean \pm SD age of patients with PMV was $64.30 \pm 4.24$ years and more than half of the patients $38(73.1 \%)$ were female, which was not significantly different from patients with very prolonged MV. The SAPS II scores at the time of ICU admission were $33.25 \pm 67.5$. Further, $16(18.83 \%)$ patients had at least one comorbidity.

Demographic and clinical characteristics of the participants $(n=85)$ according to EI status are presented in Table 1. A total of 24 patients died during this study, and the ICU mortality rate was $28.2 \%$. Non-significant increased mortality was observed in patients with late intubation (33.3\% vs. $25 \%, P=0.406)$. Several differences were observed between groups of patients; level of the nursing score $(P=0.049)$, SAPS II score at $28^{\text {th }}$ day $(P=0.019)$, hospital LOS $(P<0.001)$, and ICU LOS $(P<0.001)$ were significantly higher in patients with very prolonged $\mathrm{MV}$ than those with PMV (Table 1).

In unadjusted logistic regression, age with OR 1.083 (95\% CI: $0.989-1.185, P=0.085$ ), hospital LOS 2.617 (95\%CI: $1.628-4.205, P<0.001$, SAPA II at the admission day 1.053 (95\% CI: $0.994-1.117, P=0.081)$, SAPS II at $14^{\text {th }}$ day 1.056 (95\% CI: $\left.0.996-1.119, P=0.068\right)$, SAPS II at $28^{\text {th }}$ day 1.067 (95\% CI: $\left.1.008-1.129, P=0.025\right)$, and nursing care 0.337 (95\% CI: 0.111-1.023, $P=0.055$ ) were selected from all variables in the unadjusted model based on $P<0.1$ (Figure 1A). According to the adjusted model, two parameters were significantly associated with very prolonged MV followed by older age 1.229 (95\% CI: 1.002-1.507, $P=0.048)$ and long hospital LOS 2.996 (95\% CI: 1.676-5.356, $P<0.001$ ) (Figure $1 \mathrm{~B}$ ). The sensitivity and specificity of the multivariate model were $93.9 \%$ and $96.2 \%$. The area under the curve and standard error was $0.992 \pm 0.006(0.981-1.000)$.

\section{Discussion}

Tracheal intubation of critically ill patients is a common procedure and is frequently complicated by severe adverse events and risk of mortality, with an incidence ranging from 4.2 to $39 \%{ }^{31-33}$ In this study, we determined the characteristics associated with prolonged and very prolonged duration of EI in septic patients and the impact of this procedure on mortality. Most patients (61.2\%) had prolonged and $38.8 \%$ of patients had very prolonged duration of intubation. Our observations showed that the older age and long hospital LOS as pre-ICU stay in patients with positive sepsis at the ICU admission can prolong the duration of intubation. In addition, no significant survival difference was observed between patients with prolonged and very prolonged intubation which was consistent with the study conducted by Delbove et al. ${ }^{5} \mathrm{~A}$ causative relationship between delayed intubation and increased mortality cannot be established for sure based on an observational study, but our observation should raise suspicion on this point.

Based on the evidence, $7.6 \%$ of patients admitted to an ICU met these clinical conditions; PMV, tracheostomy,

Table 1. Demographic and Clinical Characteristics of the Participants According to El Status

\begin{tabular}{|c|c|c|c|c|}
\hline \multirow{2}{*}{ Variables } & \multicolumn{2}{|c|}{ Mechanical Ventilator } & \multirow{2}{*}{$\begin{array}{l}\text { Total patients } \\
\quad(n=85)\end{array}$} & \multirow{2}{*}{$P$ Value } \\
\hline & PMV $(n=52)$ & Very PMV $(n=33)$ & & \\
\hline Age, mean \pm SD $(y)$ & $64.30 \pm 4.24$ & $66.27 \pm 5.97$ & $65.07 \pm 5.04$ & 0.080 \\
\hline Gender, female, n (\%) & $38(73.1)$ & $19(57.6)$ & $57(67.1)$ & 0.138 \\
\hline Family engagement, high, n (\%)a & $15(28.8)$ & $12(36.4)$ & $27(31.8)$ & 0.468 \\
\hline Baseline cognitive impairment, yes, $\mathrm{n}(\%)^{\mathrm{b}}$ & $7(13.5)$ & $8(24.2)$ & $15(17.6)$ & 0.204 \\
\hline Level of nursing care, high, $\mathrm{n}(\%)^{\mathrm{c}}$ & $5(15.2)$ & $18(34.6)$ & $23(27.1)$ & $0.049^{*}$ \\
\hline Comorbidities, yes, n $(\%)^{d}$ & $10(19.2)$ & $6(18.2)$ & $16(18.8)$ & 0.904 \\
\hline Baseline sleep disturbance, yes, $\mathrm{n}(\%)^{\mathrm{e}}$ & $36(69.2)$ & $19(57.6)$ & $55(64.7)$ & 0.273 \\
\hline SAPS score, mean \pm SD (first day) & $32.09 \pm 6.22$ & $35.09 \pm 9.10$ & $33.25 \pm 7.56$ & 0.075 \\
\hline SAPS score, mean \pm SD $\left(14^{\text {th }}\right.$ day $)$ & $42.59 \pm 6.58$ & $45.78 \pm 8.99$ & $43.83 \pm 7.71$ & 0.063 \\
\hline SAPS score, mean \pm SD $\left(28^{\text {th }}\right.$ day $)$ & $37.07 \pm 6.80$ & $41.24 \pm 9.27$ & $38.69 \pm 8.06$ & $0.019^{*}$ \\
\hline Hospital LOS, mean \pm SD (day) & $33.21 \pm 2.53$ & $49.88 \pm 18$ & $39.68 \pm 13.93$ & $<0.001 *$ \\
\hline $\mathrm{ICU}$ LOS, mean $\pm \mathrm{SD}$ (day) & $71.62 \pm 1.71$ & $87.94 \pm 18.44$ & $77.95 \pm 13.97$ & $<0.001 *$ \\
\hline Mortality, n (\%) & $13(25)$ & $11(33.3)$ & $24(28.2)$ & 0.406 \\
\hline
\end{tabular}

Abbreviations: $\mathrm{El}$, endotracheal intubation; ICU, intensive care unit; PMV, prolonged mechanical ventilation; SAPS, Simplified Acute Physiology Score; MV, mechanical ventilator; LOS, length of stay.

* Statistically significant.

a As determined by having a family at the bedside for $\geq 2$ hours daily.

${ }^{\mathrm{b}}$ As determined by the six-item cognitive impairment test (6-CIT) and $>8$ score significant as cognitive impairment.

${ }^{\mathrm{c}}$ As determined by requiring $>8$ hours nursing care in an 8 -hour shift.

${ }^{d}$ As determined by the Charlson Comorbidity Index based on the International Classification of Diseases (ICD) that a score of zero indicates that no comorbidities were found and the higher score shows comorbidity.

e As determined by the Pittsburgh Sleep Quality Index (PSQI) and PSQI score > 5 indicate worse sleep quality. 

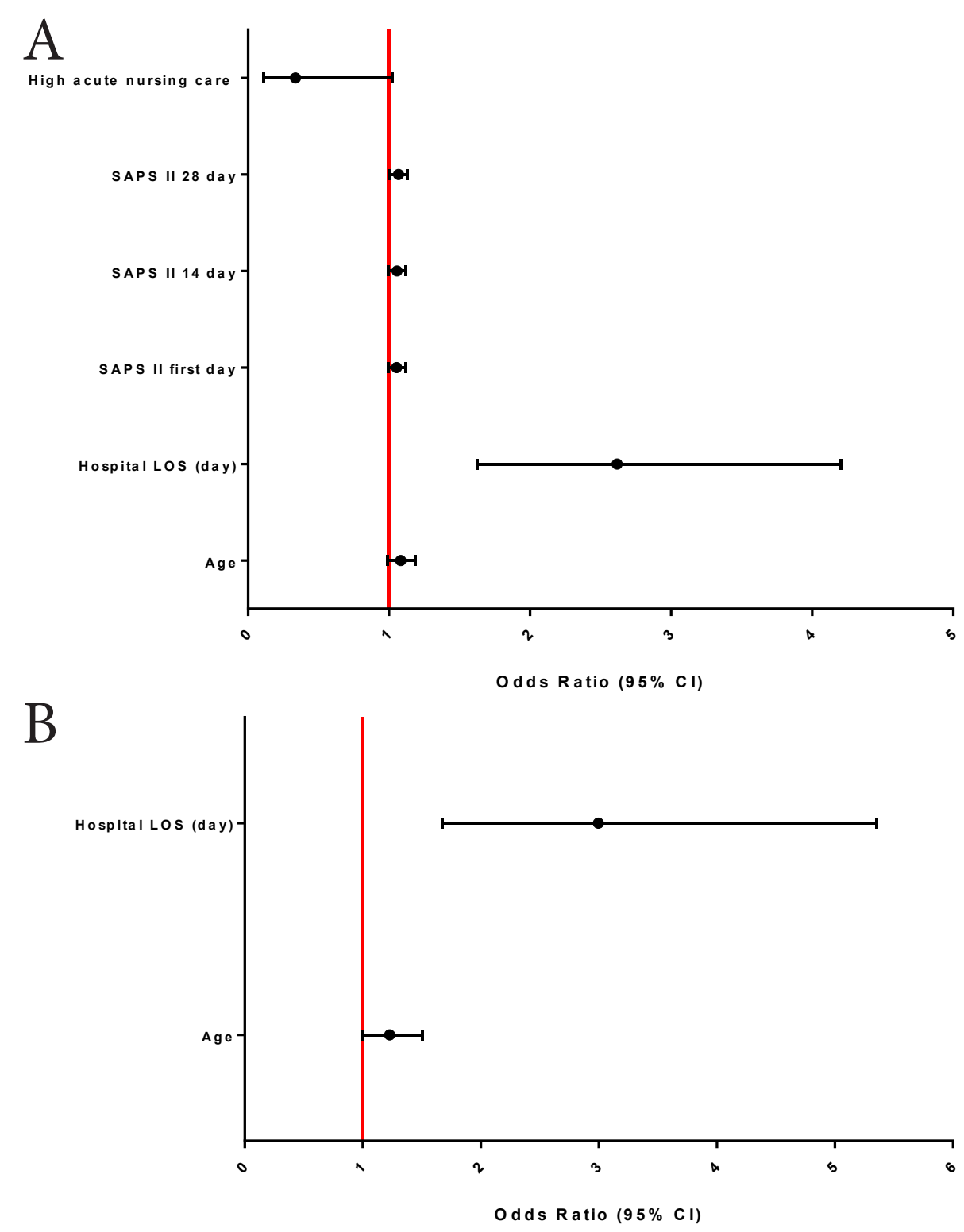

Figure 1. Univariate (A) and Multivariate (B) Binary Logistic Regression Analyses to Identify Predictive Factors for Very PMV.

stroke, traumatic, brain injury, sepsis or severe wounds, and at least eight days of ICU LOS, with a $30.9 \%$ hospital mortality. ${ }^{34}$ Many survivors may suffer from persisting physical disabilities, and reduced quality of life, even years after discharging from ICU. ${ }^{35,36}$ Several issues can lead to these limitations. Diaphragm weakness is highly prevalent in critically ill patients. It may exist prior to ICU admission and may induce the need for MV but it also frequently develops during the ICU stay. Several risk factors for diaphragm weakness have been reported, including sepsis and duration of MV. Critical illness-associated diaphragm weakness is consistently associated with poor outcomes, including increased ICU mortality, difficult weaning, and PMV. ${ }^{37,38}$ An LOS and lack of response or an insufficient level of effective therapy can lead to muscle wasting and weakness, deconditioning, recurrent symptoms, and mood alterations. ${ }^{39}$ Substantial abnormalities of the hypothalamic-anterior pituitary-peripheral hormonal axes are also present. ${ }^{40}$ Subjects under PMV may show a lower hypercapnic ventilatory response compared to successfully weaned subjects. ${ }^{41}$ In addition, the emphasis must also be on sleep disturbances in the ICU due to the possible relation between sleep deprivation and development of delirium, prolonged ICU LOS, and increased mortality. ${ }^{42}$ Sleep disturbance based on PSQI (28) was observed in $55(64.7 \%)$ patients in the current study. Of these, 36 (69.2\%) and 19 (57.6\%) patients were located in PMV and very prolonged MV groups, respectively. However, this difference between the two groups of the study was not statistically significant $(P=0.273)$.

Although we did not find any differences between PMV and very prolonged MV patients in terms of hospital mortality, evidence suggests that hospital mortality in PMV patients is significantly higher than in non-PMV patients. A population-based cohort study in an ICU in Canada, ${ }^{43}$ reported that $5 \%$ of patients underwent PMV, with $42 \%$ 
Research Highlights

\section{What Is Already Known?}

The number of patients who require PMV increased during the last decade, which generated a large population of critically ill patients who were admitted to ICU with sepsis.

\section{What Does This Study Add?}

- The older age and long hospital LOS as pre-ICU stay in patients with positive sepsis at the ICU admission can prolong the duration of intubation.

- No significant survival difference was observed between patients with PMV and very prolonged MV.

hospital mortality vs $28 \%$ of non-PMV patients. Among hospital survivors, estimated 1-year and 5-year mortalities for PMV patients were $17 \%$ and $42 \%$, respectively. A systematic analysis of the literature by Damuth et al. ${ }^{44}$ on long-term survival of PMV patients, reported a 59-62\% mortality at 1 year. Pooled mortality at hospital discharge was $29 \%$. However, only $19 \%$ were discharged home and only $50 \%$ were successfully liberated from $\mathrm{MV}^{4}{ }^{44}$

The current study's strengths include its multicenter design and for the first time, very long-term MV factors in ICU patients with sepsis at the time of ICU admission were examined. However, our study has several limitations. First, data were collected prospectively in the main study, ${ }^{20}$ but secondary data analysis was performed retrospectively. Secondly, due to the nature of the study (retrospective observational), we were not able to assess the long-term mortality, quality of life, and cognitive impairment in these patients. Thirdly, this study was retrospective, and it was not possible to describe and compare the different $\mathrm{MV}$ strategies, including a ventilator, mode and flow/pressure adjustments. Nevertheless, our results provide insight into the outcome and factors associated with prolonged and very prolonged EI in very long ICU stay patients with sepsis at the time of ICU admission.

\section{Conclusion}

Our observations showed that the older age and long hospital LOS as pre-ICU stay in patients with positive sepsis at the ICU admission can prolong the duration of intubation. In addition, no significant survival difference was observed between patients with PMV and very prolonged MV.

\section{Authors' Contributions}

FR, MS, MKH, and AV-A designed the study and were responsible for the data acquisition, data analysis, and interpretation, and both authors substantively revised and approved the submitted version of the manuscript.

\section{Conflict of Interests Disclosures}

The authors declared no potential conflicts of interest with respect to the research, authorship, and/or publication of this article.

\section{Ethical Approval}

The original study was approved by the Investigative Review Board at Baqiyatallah University of Medical Sciences, Tehran, Iran (IR.BMSU.REC.1394.451), and Shariati Hospital of Tehran University of Medical Sciences, Tehran, Iran. The patients, or their relatives, were informed about participation in the study by the physician at the time of admission with consent in all cases.

\section{References}

1. Marshall JC, Vincent JL, Guyatt G, et al. Outcome measures for clinical research in sepsis: a report of the 2 nd Cambridge Colloquium of the International Sepsis Forum. Crit Care Med. 2005;33(8):1708-1716. doi:10.1097/01. ccm.0000174478.70338.03.

2. Sakr Y, Jaschinski U, Wittebole X, et al. Sepsis in intensive care unit patients: worldwide data from the intensive care over nations audit. Open Forum Infect Dis. 2018;5(12):ofy313. doi:10.1093/ofid/ofy313.

3. Dhooria S, Agarwal R. "Early goal-directed therapy" versus "Early" and "goal-directed" therapy for severe sepsis and septic shock: time to rationalize. Lung India. 2015;32(5):521523.

4. Zhang Z, Hong Y, Smischney NJ, et al. Early management of sepsis with emphasis on early goal directed therapy: AME evidence series 002. J Thorac Dis. 2017;9(2):392-405. doi:10.21037/jtd.2017.02.10

5. Delbove A, Darreau C, Hamel JF, Asfar P, Lerolle N. Impact of endotracheal intubation on septic shock outcome: a post hoc analysis of the SEPSISPAM trial. J Crit Care. 2015;30(6):1174-1178. doi:10.1016/j.jcrc.2015.08.018.

6. Peake SL, Delaney A, Bailey M, et al. Goal-directed resuscitation for patients with early septic shock. N Engl J Med. 2014;371(16):1496-1506. doi:10.1056/ NEJMoa1404380.

7. Caironi P, Tognoni G, Masson S, et al. Albumin replacement in patients with severe sepsis or septic shock. N Engl J Med. 2014;370(15):1412-1421. doi:10.1056/NEJMoa1305727.

8. Rivers E, Nguyen B, Havstad S, et al. Early goal-directed therapy in the treatment of severe sepsis and septic shock. N Engl J Med. 2001;345(19):1368-1377. doi:10.1056/ NEJMoa010307.

9. Viires N, Sillye G, Aubier M, Rassidakis A, Roussos C. Regional blood flow distribution in dog during induced hypotension and low cardiac output. Spontaneous breathing versus artificial ventilation. J Clin Invest. 1983;72(3):935947. doi:10.1172/jci111065.

10. Manthous CA, Hall JB, Kushner R, Schmidt GA, Russo G, Wood LD. The effect of mechanical ventilation on oxygen consumption in critically ill patients. Am J Respir Crit Care Med. 1995;151(1):210-214. doi:10.1164/ ajrccm.151.1.7812556.

11. Lanone S, Taillé C, Boczkowski J, Aubier M. Diaphragmatic fatigue during sepsis and septic shock. Intensive Care Med. 2005;31(12):1611-1617. doi:10.1007/s00134-005-2748-4.

12. Demoule A, Jung B, Prodanovic $\mathrm{H}$, et al. Diaphragm dysfunction on admission to the intensive care unit Prevalence, risk factors, and prognostic impact-a prospective study. Am J Respir Crit Care Med. 2013;188(2):213-219. doi:10.1164/rccm.201209-1668OC.

13. Jaber S, Petrof BJ, Jung B, et al. Rapidly progressive diaphragmatic weakness and injury during mechanical ventilation in humans. Am J Respir Crit Care Med. 2011;183(3):364-371. doi:10.1164/rccm.201004-0670OC.

14. Epstein SK, Ciubotaru RL. Independent effects of etiology 
of failure and time to reintubation on outcome for patients failing extubation. Am J Respir Crit Care Med. 1998;158(2):489-493. doi:10.1164/ajrccm.158.2.9711045.

15. Darreau C, Martino F, Saint-Martin M, et al. Use, timing and factors associated with tracheal intubation in septic shock: a prospective multicentric observational study. Ann Intensive Care. 2020;10(1):62. doi:10.1186/s13613-020-00668-6.

16. Loss SH, de Oliveira RP, Maccari JG, et al. The reality of patients requiring prolonged mechanical ventilation: a multicenter study. Rev Bras Ter Intensiva. 2015;27(1):26-35. doi:10.5935/0103-507x.20150006.

17. Colpan A, Akinci E, Erbay A, Balaban N, Bodur H. Evaluation of risk factors for mortality in intensive care units: a prospective study from a referral hospital in Turkey. Am J Infect Control. 2005;33(1):42-47. doi:10.1016/j. ajic.2004.09.005.

18. Ye Y, Zhu B, Jiang L, et al. A contemporary assessment of acute mechanical ventilation in Beijing: description, costs, and outcomes. Crit Care Med. 2017;45(7):1160-1167. doi: $10.1097 / \mathrm{ccm} .0000000000002360$.

19. Ambrosino N, Vitacca M. The patient needing prolonged mechanical ventilation: a narrative review. Multidiscip Respir Med. 2018;13:6. doi:10.1186/s40248-018-0118-7.

20. Bashar FR, Vahedian-Azimi A, Hajiesmaeili M, et al. PostICU psychological morbidity in very long ICU stay patients with ARDS and delirium. J Crit Care. 2018;43:88-94. doi:10.1016/j.jcrc.2017.08.034.

21. von Elm E, Altman DG, Egger M, Pocock SJ, Gøtzsche PC, Vandenbroucke JP. The Strengthening the Reporting of Observational Studies in Epidemiology (STROBE) statement: guidelines for reporting observational studies. J Clin Epidemiol. 2008;61(4):344-349. doi:10.1016/j. jclinepi.2007.11.008.

22. Singer M, Deutschman CS, Seymour CW, et al. The third international consensus definitions for sepsis and septic shock (Sepsis-3). JAMA. 2016;315(8):801-810. doi:10.1001/ jama.2016.0287.

23. MacIntyre NR, Epstein SK, Carson S, Scheinhorn D, Christopher K, Muldoon S. Management of patients requiring prolonged mechanical ventilation: report of a NAMDRC consensus conference. Chest. 2005;128(6):39373954. doi:10.1378/chest.128.6.3937.

24. Quan H, Sundararajan V, Halfon P, et al. Coding algorithms for defining comorbidities in ICD-9-CM and ICD-10 administrative data. Med Care. 2005;43(11):1130-1139. doi:10.1097/01.mlr.0000182534.19832.83.

25. Hessler JB, Schäufele M, Hendlmeier I, et al. The 6-Item Cognitive Impairment Test as a bedside screening for dementia in general hospital patients: results of the General Hospital Study (GHoSt). Int J Geriatr Psychiatry. 2017;32(7):726-733. doi:10.1002/gps.4514.

26. Khaleghparast S, Joolaee S, Ghanbari B, Maleki M, Peyrovi $\mathrm{H}, \mathrm{Bahrani} \mathrm{N}$. A review of visiting policies in intensive care units. Glob J Health Sci. 2015;8(6):267-276. doi:10.5539/ gjhs.v8n6p267.

27. Nagaraj SB, Biswal S, Boyle EJ, et al. Patient-specific classification of ICU sedation levels from heart rate variability. Crit Care Med. 2017;45(7):e683-e690. doi: $10.1097 / \mathrm{ccm} .000000000002364$.

28. Buysse DJ, Reynolds CF, 3rd, Monk TH, Berman SR, Kupfer DJ. The Pittsburgh Sleep Quality Index: a new instrument for psychiatric practice and research. Psychiatry Res. 1989;28(2):193-213. doi:10.1016/0165-1781(89)90047-4.
29. Rapsang AG, Shyam DC. Scoring systems in the intensive care unit: a compendium. Indian J Crit Care Med. 2014;18(4):220-228. doi:10.4103/0972-5229.130573.

30. Kline RB. Software review: software programs for structural equation modeling: Amos, EQS, and LISREL. J Psychoeduc Assess. 1998;16(4):343-364. doi:10.1177/073428299801600407.

31. Cabrini L, Landoni G, Baiardo Redaelli M, et al. Tracheal intubation in critically ill patients: a comprehensive systematic review of randomized trials. Crit Care. 2018;22(1):6. doi:10.1186/s13054-017-1927-3.

32. Simpson GD, Ross MJ, McKeown DW, Ray DC. Tracheal intubation in the critically ill: a multi-centre national study of practice and complications. Br J Anaesth. 2012;108(5):792799. doi:10.1093/bja/aer504.

33. Cook TM, Woodall N, Harper J, Benger J. Major complications of airway management in the UK: results of the Fourth National Audit Project of the Royal College of Anaesthetists and the Difficult Airway Society. Part 2: intensive care and emergency departments. $\mathrm{Br} J$ Anaesth. 2011;106(5):632-642. doi:10.1093/bja/aer059.

34. Kahn JM, Le T, Angus DC, et al. The epidemiology of chronic critical illness in the United States*. Crit Care Med. 2015;43(2):282-287. doi:10.1097/ccm.0000000000000710.

35. Kahn JM, Benson NM, Appleby D, Carson SS, Iwashyna TJ. Long-term acute care hospital utilization after critical illness. JAMA. 2010;303(22):2253-2259. doi:10.1001/ jama.2010.761.

36. Herridge MS, Tansey CM, Matté A, et al. Functional disability 5 years after acute respiratory distress syndrome. N Engl J Med. 2011;364(14):1293-1304. doi:10.1056/ NEJMoa1011802.

37. Dres M, Goligher EC, Heunks LMA, Brochard LJ. Critical illness-associated diaphragm weakness. Intensive Care Med. 2017;43(10):1441-1452. doi:10.1007/s00134-017-4928-4.

38. Goligher EC, Dres M, Fan E, et al. Mechanical ventilationinduced diaphragm atrophy strongly impacts clinical outcomes. Am J Respir Crit Care Med. 2018;197(2):204-213. doi:10.1164/rccm.201703-0536OC.

39. Nelson JE, Cox CE, Hope AA, Carson SS. Chronic critical illness. Am J Respir Crit Care Med. 2010;182(4):446-454. doi:10.1164/rccm.201002-0210CI.

40. Van den Berghe G. On the neuroendocrinopathy of critical illness. Perspectives for feeding and novel treatments. Am J Respir Crit Care Med. 2016;194(11):1337-1348. doi:10.1164/ rccm.201607-1516CI.

41. Lee CS, Chen NH, Chuang LP, et al. Hypercapnic ventilatory response in the weaning of patients with prolonged mechanical ventilation. Can Respir J. 2017;2017:7381424. doi:10.1155/2017/7381424.

42. Boyko Y, Jennum P, Toft P. Sleep quality and circadian rhythm disruption in the intensive care unit: a review. Nat Sci Sleep. 2017;9:277-284. doi:10.2147/nss.s151525.

43. Hill AD, Fowler RA, Burns KE, Rose L, Pinto RL, Scales DC. Long-term outcomes and health care utilization after prolonged mechanical ventilation. Ann Am Thorac Soc. 2017;14(3):355-362. doi:10.1513/AnnalsATS.201610792OC.

44. Damuth E, Mitchell JA, Bartock JL, Roberts BW, Trzeciak S. Long-term survival of critically ill patients treated with prolonged mechanical ventilation: a systematic review and meta-analysis. Lancet Respir Med. 2015;3(7):544-553. doi:10.1016/s2213-2600(15)00150-2. 